\title{
Tyrosine hydroxylase and levodopa responsive dystonia
}

\author{
N A FLETCHER, * I J HOLT,* A E HARDING, ${ }^{*}$ T G NYGAARD, $\dagger$ J MALLET, $\ddagger$ C D \\ MARSDEN*
}

From the Department of Clinical Neurology, * Institute of Neurology, London, UK, Department of Neurology, College of Physicians and Surgeons, Columbia University, $\uparrow$ New York, USA, Laboratoire de Neurobiologie Cellulaire et Moleculaire, $\ddagger$ Centre National de la Recherche Scientifique, Gif-sur-Yvette, France

SUMMARY It has been suggested that a form of inherited dystonia responsive to levodopa might be due to an abnormality of the tyrosine hydroxylase gene. This hypothesis has been tested using a cDNA tyrosine hydroxylase gene probe in three families with this disorder. No evidence for genetic linkage between the disease and tyrosine hydroxylase loci was found; it is possible that the disorder results from a post-transcriptional defect confined to the brain.

Tyrosine hydroxylase (TH) is the rate limiting enzyme in the catecholamine synthetic pathway and therefore plays a central role in the function of adrenergic neurons. The TH gene has been cloned' and localised to the short arm of chromosome 11, closely linked to the loci for the beta-globin-like genes, insulin and the cellular proto-oncogene $\mathrm{H}$-ras- $1 .^{2}$

Altered catecholamine neurotransmission is thought to be important in a number of neurological and psychiatric disorders and abnormal TH function could be the basis of some of these conditions. Of interest in relation to this is the recent finding that the gene locus for one form of bipolar affective disorder is linked to that for H-ras- $1,{ }^{3}$ which is very close to the TH locus. ${ }^{4}$

Dopa responsive dystonia (DRD) is an extrapyramidal disorder consisting of dystonia and Parkinsonism, usually developing in childhood and often inherited as an autosomal dominant trait. ${ }^{5}$ Frequent diurnal fluctuation of symptoms and a dramatic and prolonged response to small doses of levodopa serve to differentiate DRD from other extrapyramidal disorders of children and young adults, particularly idiopathic torsion dystonia. These features also suggest an abnormality of dopaminergic pathways with preserved dopa decarboxylase activity and dopamine receptor function. Necropsy studies of one case of DRD showed a reduced level of TH in the

Address for reprint requests: Dr N A Fletcher, Department of Clinical Neurology, Institute of Neurology, Queen Square, London WCIN 3BG, UK.

Received 10 August 1988. Accepted 6 September 1988. striatum with minimal cell loss and hypopigmentation in the substantia nigra ${ }^{6}$ On the basis of these findings, along with the clinical and pharmacological features, it has been proposed that DRD may be due to a reduced level of TH in the nigrostriatal projection. ${ }^{7} \mathrm{~A}$ similar clinical syndrome has been described in association with deficiency of biopterin which is a cofactor for $\mathrm{TH}^{8}$

We have investigated the possibility that DRD is due to a defect of the TH gene by attempting to demonstrate linkage between the disease and restriction fragment length polymorphisms (RFLPs) detected by a TH cDNA probe, and a probe for H-Ras-1 which also maps to $11 \mathrm{p} 15.5$.

\section{Subjects and methods}

Three families (A, B and C) containing 17 individuals affected by DRD were studied. All showed autosomal dominant inheritance. Twenty-six blood samples from 16 affected and 10 normal subjects were obtained.

DNA was extracted from peripheral blood leucocytes by standard methods 9 and digested with the restriction enzymes Taq I and Bgl II under conditions recommended by the manufacturers (Northumbria Biologicals Ltd). The resulting fragments were separated by agarose gel electrophoresis and transfered to nylon membranes (Genescreen, New England Nuclear) by Southern blotting. Probes (H-Ras-1 and TH) were labelled with ${ }^{32} \mathrm{P}$ to high specific activity by the random primer method. ${ }^{10}$ Hybridisations were carried out as recommended for Genescreen except for TH which required more stringent conditions (hybridisation with $5 \%$ dextran sulphate, $2 \%$ sodium dodecyl sulphate, $1 \mathrm{M}$ sodium chloride, filters washed in $0.1 \times$ sodium chloride/sodium citrate at $65^{\circ} \mathrm{C}$ for 1 hour). Autoradiography was at $-70^{\circ} \mathrm{C}$ for $1-10$ days. 


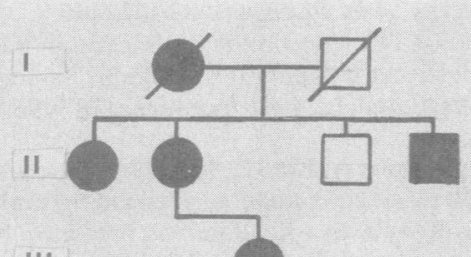

III

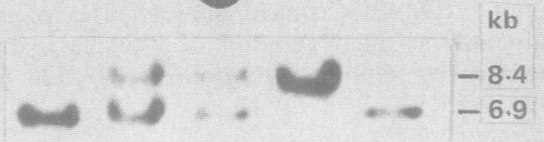

6

\section{Discussion}

Our results demonstrate that DRD is not due to an alteration of the TH gene itself; nor have we been able to show conclusively that the disease locus is closely linked to it. Systemic TH deficiency would be expected to have more widespread deleterious effects than the syndrome of DRD. The possibility remains that the disease could result from an abnormality of transcription or translation of the TH gene confined to the striatum, or the presence of brain specific isozymes. The TH gene encodes at least three TH isozymes by variable splicing of mRNA transcripts, and there is evidence that the expression of these different mRNAs varies in different parts of the brain. ${ }^{12}$ Other complex mechanisms also affect $\mathrm{TH}$ gene expression and enzyme activity. ${ }^{13}$ The underlying defect in DRD may therefore be a tissue specific defect of TH synthesis or regulation.

We thank Dr D Gardner-Medwin and Dr G Harwood for kind permission to study their patients, Dr T G Kontirikis for permission to use the H-Ras-1 probe, Dr M Davis for assistance with linkage analysis, Dr I Craig for helpful discussions and Miss M Ellison for technical help. Financial support from the Medical Research Council is gratefully acknowledged.

\section{References}

with Bgi II hybridised to a cDNA TH probe. In this pedigree there was no recombination between the TH and DRD loci, but two recombinant events occurred in the two other families.

Linkage analysis was carried out using the computer program LIPED."

\section{Results}

All three families were informative for a Bg1 II RFLP $(8.4,6.9 \mathrm{~kb}$ fragments) detected by the TH probe. Results for typed members of family $\mathrm{C}$ are shown in the fig. Lod scores for various recombination fractions between DRD and the TH and H-Ras-1 loci are shown in the table. Recombinant events between DRD and TH exclude the latter as the DRD gene. There was no evidence of linkage to H-Ras-1.

Table Lod scores for linkage between DRD and 11p markers

\begin{tabular}{lrrrrrr}
\hline \multicolumn{7}{c}{ Recombination fraction $(\theta)$} \\
& 0.0 & 0.05 & 0.10 & 0.20 & 0.30 & 0.40 \\
\hline Probe & & & & & & \\
TH & $-\infty$ & 0.371 & 0.714 & 0.756 & 0.507 & 0.191 \\
H-Ras-1 & $-\infty$ & -2.277 & -1.208 & -0.351 & -0.055 & -0.008 \\
\hline
\end{tabular}

1 Mallet J, Berod A, Blanot F, et al. Molecular genetics of tyrosine hydroxylase. In: Giuditta A, Kaplan B, Zonzely-Neurath C, eds. Role of RNA and DNA in Brain Function. Boston: Martinus Nijhoff, 1986: 57-70.

2 Craig SP, Buckle VJ, Lamouroux A, Mallet J, Craig IW. Localisation of human tyrosine hydroxylase gene to 11p15: gene duplication and evolution of metabolic pathways. Cytogenet Cell Genet 1985;42:29-32.

3 Egeland JA, Gerhard DS, Pauls DL, et al. Bipolar affective disorders linked to DNA markers on chromosome 11. Nature 1987;325:783-7.

4 Moss PAH, Davies KE, Boni C, Mallet J, Reeders ST. Linkage of tyrosine hydroxylase to four other markers on the short arm of chromosome 11. Nucleic Acids Res 1986;14:9927-32.

5 Nygaard TG, Marsden CD, Duvoisin RC. Dopa responsive dystonia. In: Fahn S, Marden CD, Calne DB, eds. Dystonia 2. Advances in Neurology, vol 50. New York: Raven Press, 1988:377-84.

6 Yokochi M, Narabayashi H, Iizuka $R$, Nagatsu $T$. Juvenile Parkinsonism-Some clinical, pharmacological and neuropathological aspects. In: Hassler RG, Christ JF, eds. Parkinson-specific Motor and Mental Disorders. Advances in Neurology, vol 40. New York: Raven Press, 1984:407-13.

7 Segawa M, Nomura Y, Tanaka S, et al. Hereditary progressive dystonia with marked diurnal fluctuationconsideration on its pathophysiology based on the 
114

characteristics of clinical and polysomnographical findings. In: Fahn S, Marden CD, Calne DB, eds. Dystonia 2. Advances in Neurology, vol 50. New York: Raven Press, 1988: 367-76.

8 Tanaka K, Yoneda M, Nakajima T, Miyatake T, Owada M. Dihydrobiopterin synthesis defect: An adult with diurnal fluctuation of symptoms. Neurology 1987;37:519-22.

9 Old JM, Higgs DR. In: Weatherall DJ ed. Methods in Haematology, vol 6. Edinburgh: Churchill Livingstone, 1983:74.

10 Feinberg AP, Vogelstein B. A technique for radiolabelling DNA restriction endonuclease fragments to high
Fletcher, Holt, Harding, Nygaard, Mallet, Marsden specific activity. Anal Biochem 1983;132:6-13.

$11 \mathrm{Ott} \mathrm{J}$. Estimation of the recombinant fraction in human pedigrees: efficient computation of the likelihood for human linkage studies. Am J Hum Genet 1974;26:58897.

12 Grima B, Lamouroux A, Boni C, Julien J-F, Javoy-Agid $F$, Mallet $J$. A single human gene encoding multiple tyrosine hydroxylases with different predicted functional characteristics. Nature 1987;326:707-11.

13 Zigmond RE. Biochemical consequences of synaptic stimulation: the regulation of tyrosine hydroxylase activity by multiple transmitters. Trends Neurosci 1985;8:63-9. 